\title{
BMJ Open Cross-cultural adaptation and psychometric properties of the Chinese version of the Communication Skills Attitude Scale among medical students in Liaoning province, China: a cross- sectional study
}

Yang Zhang, ${ }^{1}$ Gurong Jiang, ${ }^{1}$ Yihan Sun, ${ }^{1}$ Xia Zhao, ${ }^{2}$ Xiaosong $\mathrm{Yu}^{2}$

To cite: Zhang Y, Jiang G, Sun Y, et al. Cross-cultural adaptation and psychometric properties of the Chinese version of the Communication Skills Attitude Scale among medical students in Liaoning province, China: a cross-sectional study. BMJ Open 2018;8:e020931. doi:10.1136/ bmjopen-2017-020931

- Prepublication history and additional material for this paper are available online. To view please visit the journal (http:// dx.doi.org/10.1136/bmjopen2017-020931).

Received 5 December 2017 Revised 25 June 2018 Accepted 16 August 2018

Dheck for updates

(C) Author(s) (or their employer(s)) 2018. Re-use permitted under CC BY-NC. No commercial re-use. See rights and permissions. Published by BMJ.

${ }^{1}$ Institute of International Health Professions Education and Research, China Medical University, Shenyang, China

${ }^{2}$ The First Affiliated Hospital, China Medical University, Shenyang, China

Correspondence to Professor Xiaosong Yu; xiaosongyu1959@163.com

\section{ABSTRACT}

Objectives The aims of this study were to develop the Chinese version of the Communication Skills Attitude Scale (CSAS-Ch) in order to test the psychometric properties of the modified instrument.

Design A cross-sectional study was conducted in September 2016 to evaluate the attitudes of Chinese medical students towards communication skills learning using CSAS at China Medical University.

Participants The study recruited 510 fifth-year medical students by cluster sampling.

Methods Cronbach's $\alpha$ coefficients were calculated for the entire questionnaire and for the subscales to evaluate the internal consistency of the CSAS-Ch. In order to determine the structure underlying the CSAS, the scale was factor analysed using maximum likelihood extraction and the oblique rotation method.

Results Of the 510 medical students, 492 (96.5\%) completed the questionnaire. Cronbach's $\alpha$ coefficient for the CSAS scale was 0.897 . Exploratory factor analysis showed that the four-factor structure accounted for $59.8 \%$ of the variance and produced an acceptable fit to the data. Conclusions The modified CSAS-Ch can be used to evaluate attitudes towards communication skills. Further Future research for improving the teaching methods for communication skills should explore the relationship between medical students' attitudes and the demographic characteristics.

\section{INTRODUCTION}

Good communication skills (CS) are essential for effective clinical practice and the core competency of doctors. In modern China, the conflicts between doctors and patients have become increasingly serious ${ }^{1}{ }^{2}$; with common reports that doctors or nurses were injured by patients or their family members. Additionally, poor communication problems between doctors and patients have become the main cause of medical disputes and
Strengths and limitations of this study

- To our knowledge, there is only one study which explore the Communication Skills Attitude Scale (CSAS) for Chinese medical students.

- Internal consistency and the structure validity of the CSAS were examined with acceptable psychometric properties for assessing Chinese medical students' attitudes towards learning communication skills (CS).

- The factors that comprise this scale may provide educators helpful suggestions for promoting CS teaching.

- The sample used only one medical college, resulting in a study population that may not be representative of all Chinese medical students.

medical malpractice. ${ }^{3} 4$ A survey from the Chinese Association of Physicians found that for all medical disputes involving physicians, less than $20 \%$ were due to technical reasons, and more than $80 \%$ were due to the doctor's behaviour towards the patient, CS, medical ethics and other issues. ${ }^{56}$ Because they might lack professional knowledge or patience, medical students and interns will frequently be involved in conflicts with patients and their families during doctor-patient communications. Studies have shown that at present, medical students appear to be nervous or timid, unfriendly and insecure regarding their medical expertise. ${ }^{78}$

The International Medical Education Council, which was established in 1999, considers CS to be one of the seven major categories of the Global Minimum Basic Requirements for Undergraduate Education. ${ }^{9}$ In 2008, the Ministry of Education in China issued the Standards for Basic Medical 
Education. The Standards clearly require that graduates of medical programmes be able to communicate effectively with patients and their families, and with doctors, nurses and other healthcare professionals. ${ }^{10}$

In response to the Standards, many medical schools have introduced new programmes for teaching CS, and others are already using well-developed programmes from other countries. ${ }^{11}{ }^{12}$ Student attitudes are defined as positive or negative evaluations of objects. ${ }^{13}$ The assessment of attitude is important for analysing the behaviour, because a change in attitude will result in changes in behaviour. ${ }^{13} 14$ Negative attitudes among medical students represent a substantial obstacle to learning CS. The understanding of medical students' attitudes towards and beliefs about learning CS is fundamentally important for academic decision-makers, curriculum designers and teachers. ${ }^{15}$

The most widely used way accepted method for measuring to measure the attitude towards CS is the Communication Skills Attitude Scale (CSAS, Rees $e t a l$ ), which was developed by Rees et al. It aimed to measure students' attitudes towards learning CS. The CSAS uses a two-factor scale, namely positive and negative attitudes. During the last decade, this scale has been evaluated at medical schools in the UK, ${ }^{16}$ Norway, ${ }^{17}$ South Korea, ${ }^{18}$ Germany, ${ }^{19}$ Turkey, ${ }^{20}$ Western Saudi Arabia ${ }^{21}$ and other countries, resulting in several different factor scales. For example, two factors (positive and negative attitudes) were derived from the scale in the UK. Although these studies in different countries put forward different factors of the scale, such as two factors (positive attitudes and negative attitudes) in the UK, five factors (Facilitating interpersonal skills, the Importance of the within a medical context, Motivation, Assessment and Overconfidence) in the Korea and three factors (Learning, Importance and Respect) in the Norway. The extracted factors explained $56.74 \%, 55.81 \%$ and $47.90 \%$ of the variance, respectively. The results of the study in UK, South Korean and Norway indicated good internal consistency. Only one study in South China was conducted with five factors of the CSAS accounting for $54.60 \%$ of the variance for the second-year and fourth-year medical students. ${ }^{22}$ As the studies in the South Korea and South China proposed five factors with the East Asian culture, we hypothesised that the Chinese version of the CSAS (CSAS-Ch) will provide the acceptable psychometric properties with five factors for medical students in North China. The purpose of this study was to adapt the CSAS-Ch to medical students and to test the psychometric properties of the modified instrument.

\section{METHODS AND ANALYSIS}

\section{Participants and procedures}

We recruited 510 fifth-year medical students from China Medical University (via cluster sampling). The study was conducted prior to students' first clinical rotation in 2016 and after their basic clinical skills training. The 5-year medical curriculum of medical colleges is divided into 2 years of basic science, 2 years of clinical medicine and 1 year of internship training in China. Medical students are admitted from high school. All of the participants were from fifth-year medical students at China Medical University by cluster sampling. Eight investigators were recruited to assist with dissemination of the survey through the Student Association of Science and Technology. These investigators were trained and familiar with the purpose and specific content of this scale. The self-filling questionnaires were handed out to participants and completed individually. Participants were informed that their responses would remain anonymous.

\section{Instrument}

The questionnaire was divided into two parts: part A requested demographic information such as age, gender, ethnicity and education level, while part B used a validated scale developed by Rees et al to measure students' attitudes towards CS. This scale is the most commonly used method for assessing student attitudes towards learning. The scale is divided into two subscales: the Positive Attitude Scale (PAS) and the Negative Attitude Scale (NAS). Each of these scales consisted of 13 items, which were rated on a 5-point scale corresponding to opinions ranging from 'strongly agree' to 'strongly disagree'. The scores for every scale ranged from 13 to 65, with higher scores revealing stronger positive or negative attitudes towards learning CS.

\section{Cross-cultural adaptation}

The translation process was carried out in accordance with the rules for cross-cultural adaptation. ${ }^{23}$ Forward translation of the CSAS was independently performed by two professional translators (one professional translator and one non-medical professional translator). A single Chinese version was created following discussion and consensus among the two translators and the principal investigator. Two bilingual translators, who were blind to the original English version, back translated the temporary Chinese version into English. A professional bilingual medical education expert compared both of these back-translated English versions with original version of CSAS to derive a final version that did not differ from the original version in translation. An expert committee was formed which consisted of the researchers, translators and $\mathrm{CS}$ teachers. Following a committee discussion regarding the translated version, an approved version was created for field testing. The approved CSAS-Ch was pretested on 30 fifth-year medical students. This selected sample was chosen to be representative of population age, sex and education level. During the pretesting, participants were asked to complete the CSAS-Ch. The participants were queried regarding their understanding of the actual meaning of the CSAS-Ch on completion. Minor corrections were made to improve the sentence structure of the instructions to make it easier to understand, and the final CSAS-Ch was completed. 
Only medical students who gave written informed consent were enrolled in the study. All students were informed about the purpose of the study.

\section{Data analysis}

Missing data were replaced by the median. The Cronbach's $\alpha$ coefficients were calculated for the entire questionnaire and for each subscale, to evaluate the internal consistency of the CSAS-Ch. A Cronbach's $\alpha$ coefficient of $\geq 0.70$ was considered to be an acceptable level of internal consistency. ${ }^{24}$ In order to determine the structure underlying the CSAS, factor analysis using principal component analysis with direct oblimin rotation was used. ${ }^{25}$ Subscales were constructed based on factor loading, with scores being reversed where necessary.

As this study was concerned only with the internal consistency of scale, test-retest and inter-rater reliability were not calculated. All the psychometric properties of the scale were tested according to the recommendations of the Consensus $\square$ based Standards for the selection of health Measurement Instruments (COSMIN) group. The data were analysed using SPSS V.22.0 (SPSS) and LISREL V.8.5 software for Windows. A $\mathrm{p}<0.05$ was considered to be statistically significant.

\section{Patient and public involvement}

No participants were involved in developing the hypothesis, the specific aims or the research questions, nor were they involved in developing plans for design or interpretation of study results or write up of the manuscript. There are no plans to disseminate the results of the research to study participants.

\section{RESULTS}

\section{Sociodemographic characteristics of the study sample} ( $\mathrm{n}=492)$

Of the 510 fifth-year medical students invited to participate in the study, 492 (96.5\%) completed the questionnaire to satisfaction. Sociodemographic characteristics of the study sample are reported in table 1 .

\begin{tabular}{|c|c|c|}
\hline Characteristic & No & Percentage (\%) \\
\hline \multicolumn{3}{|l|}{ Age in years } \\
\hline $20-23$ & 438 & 89.0 \\
\hline $24-26$ & 54 & 11.0 \\
\hline \multicolumn{3}{|l|}{ Gender } \\
\hline Male & 209 & 42.7 \\
\hline Female & 283 & 57.5 \\
\hline \multicolumn{3}{|l|}{ Ethnicity } \\
\hline Han nationality & 444 & 90.3 \\
\hline Ethnic minorities & 48 & 9.7 \\
\hline
\end{tabular}

\section{Cross-cultural adaptation}

The translation of most items had reached a consensus after expert committee's discussion except one item. The literal translations of 'Learning CS is interesting' and 'Learning CS is fun' have similar meanings in the Chinese language. Therefore, the expert committee proposed an alternative word usage that, while common in Chinese, translates back to English as 'Learning CS is happy'. All the students in pretest period believed that the scale was easy to understand.

\section{Internal consistency of the CSAS-Ch}

After reversing the scores for items 1 and 22, the internal consistency of the scale was $\alpha=0.897$. The Cronbach's $\alpha$ coefficients of the four factors were $\alpha=0.771, \alpha=0.601$, $\alpha=0.637$ and $\alpha=0.704$. Items scores and Cronbach's $\alpha$ coefficients for each factor were reported in table 2.

\section{Factor structure}

The Kaisex-Meyer-Olkin measure was 0.925, and Bartlett's test of sphericity yielded a $\mathrm{p}<0.001$, both results indicating that factor analysis could be performed. Initial exploratory factor analysis revealed factors with eigenvalues greater than 1 , accounting for $59.78 \%$ of the variance. The original validation offered a two-factor solution with 13 items per factor. A four-factor solution based on the results was reported in the rotated component matrix (table 3). Based on a factor load $>0.4$ and more than the other three subload of $\geq 0.10$ standard, item 7 (Learning CS is interesting) and item 18 (When applying to become doctor, I thought that learning CS was a really good idea) were deleted because they loaded too similarly with multiple factors. The 24 items of the CSAS-Ch yielded a four-factor solution (see online supplementary appendix).

As table 3 shows, factor 1, named 'Importance of CS', indicated the values that learning CS would be useful and facilitate interpersonal skills with both colleagues and patients. The factor showed how CS learning would be important for medical practice and corresponds to the components of the 'Respecting' mentioned by Anvik et $a l^{17}$ and the 'Facilitation of interpersonal skills' described by Ahn $e t a l{ }^{18}$

Factor 2 had nine items. We named this factor 'Negative beliefs' because the factor reflected the negative attitudes of CS learning and the difficulty in achieving mastery, which corresponds to the components of negative attitudes described by Rees et al. ${ }^{16}$

The items in factor 3, termed 'Motivation', represented the students' willingness to learn CS. Factor 4 was termed 'Assessment' because the items were about negative attitudes on assessment.

\section{Correlations among the factors of the scale}

The correlations between each factor were reported by Spearman's correlation coefficient in table 4 . 
Table 2 Items scores and internal consistency of each factor

Item

Mean \pm SD

Factor 1: importance of communication skills $(\alpha=0.771)$

(1) In order to be a good doctor, I must have good CS.

$4.57 \pm 0.73$

(4) Developing my CS is just as important as developing my knowledge of medicine.

$4.48 \pm 0.87$

(5) Learning CS has helped me or will help me respect patients.

$4.46 \pm 0.81$

(9) Learning CS has helped or will facilitate my ability to work as a team member.

$4.44 \pm 0.83$

(10) Learning CS has improved my ability to communicate with patients.

$4.43 \pm 0.82$

(14) Learning CS has helped or will help me respect my colleagues.

$4.36 \pm 0.93$

(16) Learning CS has helped or will help me recognise patients' rights regarding confidentiality and

$4.30 \pm 0.91$ informed consent.

(21) I think learning CS is very useful for my medical degree.

$4.38 \pm 0.94$

(25) Learning CS is important because my ability to communicate is a lifelong skill.

$4.41 \pm 1.04$

Factor 2: negative beliefs ( $\alpha=0.601$ )

(2) I cannot see the point in learning CS. *

$1.89 \pm 1.21$

(6) I have not got time to learn CS.

$2.25 \pm 1.21$

(8) I cannot be bothered to attend sessions on CS.

$2.20 \pm 1.33$

(11) CS teaches the obvious and then complicates it.

$2.48 \pm 1.46$

(13) Learning CS is too easy.

$2.68 \pm 1.13$

(15) I find it difficult to trust the information on CS provided by non-clinical lecturers.

$2.84 \pm 1.39$

(19) I do not need good CS to be a doctor.

$2.05 \pm 1.36$

(24) I find it difficult to take CS learning seriously.

$2.40 \pm 1.29$

(26) CS learning should be left to psychology students, not medical students.

$2.17 \pm 1.31$

Factor 3: motivation $(\alpha=0.637)$

(12) Learning CS is fun.

$4.18 \pm 0.99$

(17) CS teaching would be more appealing if it sounded more like a science subject.

(23) Learning CS is applicable to learning medicine.

$4.22 \pm 1.03$

Factor 4: assessment $(\alpha=0.704)$

(3) Nobody is going to fail his or her medical degree for having poor CS.

$2.71 \pm 1.20$

(20) I find it hard to admit that I have some problems with my CS.

$2.98 \pm 1.19$

(22) My ability to pass exams will get me through medical school rather than my ability to communicate. ${ }^{*} 1.63 \pm 1.10$

*Item was negatively phrased and reverse scored.

CS, communication skills.

\section{DISCUSSION}

This study confirmed that the modified CSAS-Ch has good internal consistency and structure validity for assessing Chinese medical students' attitudes towards learning CS. The results showed that a four-factor solution was appropriate for identifying the components of medical students' attitudes towards learning CS. We obtained the following four factors that explained a major portion of the variance: 'Importance of CS', 'Negative beliefs', 'Motivation' and 'Assessment'. These four factors were also shown to have good internal consistency for the items within each of the four factors. Additionally, there were significant correlations among the PAS and NAS factors. These findings suggest that the 24-item, modified four-factor solution is acceptable for use in future research.

Exploratory factor analysis revealed that CSAS-Ch had four factors that were different from those in the CSAS used in the UK (Positive and Negative attitudes) ${ }^{16}$ Korea (Facilitating interpersonal skills, Importance within a medical context, Motivation, Assessment and Overconfidence $)^{18}$ and Norway (Learning, Importance, Respect). ${ }^{17}$ Item 7 (Learning CS is interesting) and item 18 (When applying to be a doctor, I thought that learning CS was a really good idea) were deleted because they had similar factor loading with multiple factors. Some studies also describe elimination of items. ${ }^{17} 18$ The factor solution for our sample does not replicate any of the other factor structures described in research literature. The variety of validation results can be ascribed to translation. It might also be accounted for by different cultural backgrounds and variations in the processes used in different countries to develop CS curricula. ${ }^{18}$ Therefore, the attitudes of medical students towards each item in these scales would also be inconsistent. Although the extracted 


\begin{tabular}{|c|c|c|c|c|}
\hline \multirow[b]{2}{*}{ Item } & \multicolumn{4}{|l|}{ Factor } \\
\hline & 1 & 2 & 3 & 4 \\
\hline 1 & 0.760 & -0.131 & -0.164 & 0.112 \\
\hline 4 & 0.778 & -0.088 & -0.166 & 0.042 \\
\hline 5 & 0.691 & -0.162 & -0.142 & 0.141 \\
\hline 9 & 0.822 & -0.130 & -0.071 & -0.004 \\
\hline 10 & 0.746 & -0.161 & 0.107 & -0.039 \\
\hline 14 & 0.628 & -0.184 & 0.498 & 0.023 \\
\hline 16 & 0.771 & -0.115 & 0.130 & 0.007 \\
\hline 21 & 0.744 & -0.124 & 0.194 & -0.316 \\
\hline 25 & 0.666 & -0.123 & 0.132 & -0.454 \\
\hline $2^{*}$ & -0.156 & 0.763 & 0.343 & -0.072 \\
\hline $6^{*}$ & -0.159 & 0.721 & 0.325 & -0.105 \\
\hline $8^{*}$ & -0.190 & 0.738 & 0.079 & -0.021 \\
\hline $11^{*}$ & -0.077 & 0.656 & -0.213 & -0.053 \\
\hline $13^{*}$ & 0.089 & 0.650 & -0.191 & 0.072 \\
\hline $15^{*}$ & -0.082 & 0.752 & -0.251 & 0.075 \\
\hline $19^{*}$ & -0.233 & 0.769 & -0.068 & 0.106 \\
\hline $26^{*}$ & -0.187 & 0.743 & 0.080 & 0.194 \\
\hline $24^{*}$ & -0.186 & 0.715 & -0.004 & 0.300 \\
\hline 12 & 0.312 & -0.056 & 0.642 & 0.121 \\
\hline $17^{*}$ & 0.188 & 0.179 & 0.555 & -0.120 \\
\hline 23 & 0.413 & 0.012 & 0.489 & -0.219 \\
\hline 3 & -0.032 & 0.315 & 0.333 & 0.414 \\
\hline 20 & 0.153 & 0.468 & -0.046 & 0.358 \\
\hline 22 & 0.167 & 0.406 & 0.196 & 0.578 \\
\hline
\end{tabular}

*Items are negative, and the scores were reversed before factor analysis. ${ }^{*}$ Items are bolded per column to indicate the relevant factor in which they belong.

factors between these countries varied, the overall factors showed that CS learning facilitates communication with colleagues and patients and enables the students to respect their counterparts (items 5, 9, 10, 14 and 16). Our first factor, 'Importance of CS' is similar to the UK 'Positive' factor, the Korean factor 'Facilitating interpersonal skills' and the Norwegian factor 'Respect'. The study by Rees $e t$ al focused on the measurement of positive and negative attitudes, whereas Norwegian investigator aimed to measure both 'emotional' and 'cognitive' attitudes.

\begin{tabular}{lccccc}
\hline Table 4 & \multicolumn{6}{l}{ Correlations among the factors } \\
\hline Factor & $\mathbf{1}$ & $\mathbf{2}$ & $\mathbf{3}$ & $\mathbf{4}$ \\
\hline 1 & - & & & \\
2 & $-0.304^{*}$ & - & & \\
3 & $0.728^{*}$ & $-0.139^{*}$ & - & \\
4 & $0.109 \dagger$ & $0.207^{*}$ & 0.068 & - \\
\hline
\end{tabular}

${ }^{*}$ Correlation is significant at the 0.01 level (two tailed).

†Correlation is significant at the 0.05 level (two tailed).
The current study focused on the internal structure of the scale, which was also similar with the Korean study. ${ }^{18}$ There were also significant correlations among the factors except for between F3 'Motivation' and F4 'Assessment'. Some studies also examined the correlations among the factors with the significant correlations by Laurence $e t$ al in the USA and by Ahn et al in the South Korean. ${ }^{186}$ The results of correlation analysis of the four factors showed that F1 (Importance of CS) was strongly correlated with F3 (Motivation). This shows that if medical students had a better understanding of the importance of communication, their motivation for learning may also be enhanced. The possibility of retaining negative beliefs and negative attitudes will be reduced in previous study. ${ }^{27}$ The negative attitudes and beliefs of medical students towards learning CS have also been found to be affected by other factors. ${ }^{28-30}$ It is our assertion that teachers do not have to become entangled in the negative attitudes of medical students. Instead, they can strengthen the students' positive attitudes by establishing scientifically based teaching content and changing their teaching methods in such a way as to enhance the motivations of medical students.

During the last two decades, this scale has been evaluated in several countries, resulting in several different factor scales (such as 2, 3, 4 and 5 factors). It shows that the variation of the factor structure of the scale was large when the scale was applied in different culture. ${ }^{16-1826}$ So it may be not suitable to conduct the cross-cultural validity to test the hypothesised factor structure based on the factor structure of the original scale in China population.

Although methodologically sound, the current study has strengths and limitations. For example, the factors of the scale proposed in the study provide educators helpful suggestions for promoting CS teaching. However, the study sample was only derived from one medical university in China, resulting in a study population that might not be representative of all Chinese medical students. Further studies with varying levels of educational and participants from additional centres are needed to confirm the stability of the structure of the scale.

Limitations withstanding, the current study has both theoretical and practical implications. First, the importance of CS in school should be emphasised early in the curriculum of medical students in order to motivate them. Second, medical students' CS can be enhanced through active participation in courses that teach basic CS, which suggest that clinical science courses and courses on medical humanism should be coordinated. Appropriate content and methods for teaching CS should be developed. Increasing the rate of student participation and improving CS are vital, and should result in many positive outcomes, including increased patient satisfaction and patient compliance. ${ }^{31} 32$

\section{CONCLUSIONS}

The CSAS-Ch was an acceptable instrument for evaluating a large sample of Chinese medical students. The scale will 
help measure the changes in attitudes among Chinese medicine students towards learning CS and explore the relationship between medical students' attitudes and demographic characteristics such as gender and education level, thus making it possible to promote the teaching of CS as well as to reform the teaching curriculum for CS.

Acknowledgements We thank all the students and experts in participating in the study.

Contributors $X Y$ designed the research. $Y Z$ and $X Z$ participated in the data collection. YZ and YS wrote the manuscript. $Y Z$ and GJ participated in data analysis. All authors read and approved the final manuscript.

Funding This study was supported by the consulting project of Chinese Academic of Engineering (Grant Number 2016-ZD-11-01-01).

Competing interests None declared.

Patient consent Not required.

Ethics approval The study was approved by the ethical committee of China Medical University.

Provenance and peer review Not commissioned; externally peer reviewed.

Data sharing statement The unpublished data are available to all readers on request. The de-identified data can be provided by email.

Open access This is an open access article distributed in accordance with the Creative Commons Attribution Non Commercial (CC BY-NC 4.0) license, which permits others to distribute, remix, adapt, build upon this work non-commercially, and license their derivative works on different terms, provided the original work is properly cited, appropriate credit is given, any changes made indicated, and the use is non-commercial. See: http://creativecommons.org/licenses/by-nc/4.0/.

\section{REFERENCES}

1. Shi J, Wang S, Zhou P, et al. The frequency of patient-initiated violence and its psychological impact on physicians in china: a cross-sectional study. PLoS One 2015;10:e0128394.

2. Hou J, Michaud C, Li Z, et al. Transformation of the education of health professionals in China: progress and challenges. Lancet 2014;384:819-

3. Hu W, Song Y, Zhong X, et al. Improving doctor-patient communication: content validity examination of a novel urinary system-simulating physical model. Patient Prefer Adherence 2016;10:2519-29.

4. Jiao M, Ning N, Li Y, et al. Workplace violence against nurses in Chinese hospitals: a cross-sectional survey. BMJ Open 2015;5:e006719.

5. Association CMD. The research report of "medical dispute" in some provinces and cities nationwide in China. China Health Industry 2007;2:57-9.

6. Li N, Lu Q, Rong WH. Papers on medical disputes-induced group events in 2006-2013: a bibliometric analysis. Chinese Journal of Medical Library and Information Science 2014:23:50-2.

7. Wu Y, Gao J, Fan WB. How to improve the communication between clinical students and patients? Medicine and Philosophy 2007;3:43-4.

8. Liu X, Rohrer W, Luo A, et al. Doctor-patient communication skills training in mainland China: a systematic review of the literature. Patient Educ Couns 2015;98:3-14.

9. Schwarz AW, Roy M. Minimum essential requirements and standards in medical education. Med Teach 2000;22:555-9.
10. Wang Q. Development and current status of medical education accreditation in the World. Fudan Education Forum 2011;9:86-91.

11. Stein T, Frankel RM, Krupat E. Enhancing clinician communication skills in a large healthcare organization: a longitudinal case study. Patient Educ Couns 2005;58:4-12.

12. Trickey AW, Newcomb AB, Porrey M, et al. Two-year experience implementing a curriculum to improve residents' patient-centered communication skills. J Surg Educ 2017;74:e124-e132.

13. Olson JM, Zanna MP. Attitudes and attitude change. Annu Rev Psychol 1993;44:117-54.

14. Sah S. Conflicts of interest and your physician: psychological processes that cause unexpected changes in behavior. J Law Med Ethics 2012;40:482-7.

15. Kaplonyi J, Bowles KA, Nestel D, et al. Understanding the impact of simulated patients on health care learners' communication skills: a systematic review. Med Educ 2017;51:1209-19.

16. Rees C, Sheard C, Davies S. The development of a scale to measure medical students' attitudes towards communication skills learning: the Communication Skills Attitude Scale (CSAS). Med Educ 2002;36:141-7.

17. Anvik T, Gude T, Grimstad H, et al. Assessing medical students' attitudes towards learning communication skills--which components of attitudes do we measure? BMC Med Educ 2007;7:4.

18. Ahn S, Yi YH, Ahn DS. Developing a Korean communication skills attitude scale: comparing attitudes between Korea and the West. Med Educ 2009;43:246-53.

19. Busch AK, Rockenbauch K, Schmutzer G, et al. Do medical students like communication? Validation of the German CSAS (Communication Skills Attitude Scale). GMS Z Med Ausbild 2015;32.

20. Harlak H, Dereboy C, Gemalmaz A. Validation of a Turkish translation of the Communication Skills Attitude Scale with Turkish medical students. Educ Health 2008;21:55.

21. Alotaibi FS, Alsaeedi A. Attitudes of medical students toward communication skills learning in Western Saudi Arabia. Saudi Med J 2016;37:791-5.

22. Jr I DXT, Hh D, et al. A tool to measure Chinese medical students attitues towards Doctor-patient communication skill learning: Developing a Chinese version of Communication Skills Attitude Scale. Medicine and Philosophy 2014;1:58-61.

23. Beaton DE, Bombardier C, Guillemin F, et al. Guidelines for the process of cross-cultural adaptation of self-report measures. Spine 2000;25:3186-91.

24. Tan G, Jensen MP, Thornby Jl, et al. Validation of the brief pain inventory for chronic nonmalignant pain. J Pain 2004;5:133-7.

25. Rovine MJ, Molenaar PC. A structural modeling approach to a multilevel random coefficients model. Multivariate Behav Res 2000;35:51-88.

26. Laurence B, Bertera EM, Feimster T, et al. Adaptation of the Communication Skills Attitude Scale (CSAS) to dental students. $J$ Dent Educ 2012;76:1629-38.

27. Shih C-C, Gamon J. Web-based learning: relationships among student motivation, attitude, learning styles, and achievement. $J$ Agric Educ 2001;42:12-20.

28. Cleland J, Foster K, Moffat M. Undergraduate students' attitudes to communication skills learning differ depending on year of study and gender. Med Teach 2005;27:246-51.

29. Arlt $D$, Wolling J. The refugees: threatening or beneficial? Exploring the effects of positive and negative attitudes and communication on hostile media perceptions. Global Media Journal 2016;6:1-21.

30. Molinuevo B, Aradilla-Herrero A, Nolla M, et al. A comparison of medical students', residents' and tutors' attitudes towards communication skills learning. Educ Health 2016;29:132.

31. Zolnierek KB, Dimatteo MR. Physician communication and patient adherence to treatment: a meta-analysis. Med Care 2009;47:826-34.

32. Stewart MA. Effective physician-patient communication and health outcomes: a review. CMAJ 1995;152:1423. 